\title{
THE MAIN ROLE OF VIDEO ADS' STRUCTURE ON SOCIAL MEDIA ENGAGEMENT
}

\author{
Sónia de Almeida Ferreira ${ }^{1}$, Sara Santos ${ }^{2}$ and Pedro Espírito Santo ${ }^{3}$ \\ ${ }^{1}$ Center for Studies in Education and Innovation, School of Education, Polytechnic of Viseu, Portugal \\ ${ }^{2}$ School of Education, Polytechnic of Viseu, Portugal \\ ${ }^{3}$ School of Technology and Management of Oliveira do Hospital, Polytechnic of Coimbra, Portugal
}

\begin{abstract}
Social networks play an important role in the life of today's societies. Brands create and share advertising video ads on social media networks and, in the context of the COVID-19 pandemic, social networks have allowed brands to communicate with their consumers, and creativity and narrative structures were important to consumers. Brands are producing video ads that show consumers' day context in order to obtain greater social media engagement. Considering that, this paper aims to study whether that goal is being achieved. The empirical research, from which we obtained 427 responses and which was tested using structural equations using the AMOS software, allows to conclude that creativity, the structure of the narrative and the consumer's congruence with the brand are determinants of engagement in social media. Further, presents practical and theoretical recommendations.
\end{abstract}

\section{KEYWORDS}

Video Ads, Narrative Structure, Creativity, Brand Congruence, Social Media Engagement

\section{INTRODUCTION}

The human capacity to create narratives as a way of communicating is one of the oldest tools we know. Disciplines such as marketing and advertising easily recognize the power of storytelling and the importance of implementing approaches that provoke individuals' attitudes and behavior.

With the new media, brands have access to new ways to disseminate information and enhance collaboration, community, conversation and sharing between consumers and among them and brands (Hennig-Thurau et al., 2010). Thus, social media platforms have been adopted in a large part of marketing strategies to enhance consumer engagement (Harrigan, Evers, Miles, \& Daly, 2017) through stories (Brechman \& Purvis 2015).

We agree that the receptivity to advertising messages differs from individual to individual, considering their contexts and demographic, social, educational characteristics, among others, but, according to Brechman and Purvis (2015), they are increasingly willing to be transported to the advertising narrative, which further enhances this area of expertise.

On the other side, as consumers prefer products congruent with their self-concept, self-congruence could trigger emotional, attitudinal and behavioural reactions to the brand (Grohmann, 2009). So, engage consumers special through social media platforms is essential to create an effective strategic role in branding and advertising.

Considering the framework, this study aims to analyze whether the advertising videos produced by the brands that show, more and more, the daily lives of the public are being effective in engaging in social media. Specifically, study the effects of creativity and the structure of narratives on social media engagement. Additionally, we studied the mediating effects of brand congruence. A questionnaire survey was applied and the data obtained were tested using structural equations in the AMOS software. 


\section{LITERATURE REVIEW}

\subsection{Video Ad's Narrative Structure and Creativity}

It is important to clarify the concept of transportation for the advertising narrative, initially proposed by Green, in 1996. According to the author, it defines the process of transporting the individual to a fictional reality created from a narrative, creating evident effects on their beliefs, attitudes and behaviors (Green \& Clark, 2012), losing access to the real and experiencing the emotions evoked by history (Green \& Block, 2000).

In terms of the structure narrative creation, Escadas (2007) states that the ads are not openly persuasive. They present an affective component that unconsciously directs the consumer. Structurally, the narratives are based on a plot with incidents and surprises, on characters to whom conflicts and events happen and at a climax moment where the resolution of the story is presented (Snowden, 1999; van Laer et al., 2014) and the major conflict finally resolved.

According to Bruner (Brechman \& Purvis, 2015), the traditional definitions propose that the narratives present a chronology, organizing the events with a temporal dimension, finding a beginning, middle and end. In addition, they seek to achieve causality, that is, the structuring of the elements of history in an organized manner that allows for causal inference. In addition to including emotional appeals, narratives are endowed with structural elements that "provide context, usually establishing an environment that has physical, social and temporal components, and the story is further enhanced with the use of images to guide consumers' imaginations, involvement or immersion in the story (Brechman \& Purvis, 2015). Along with information and entertainment, creativity is also understood as a constructor of consumer attitudes and associations towards ads (Gao \& Koufaris, 2006; Taylor, Lewin, \& Strutton, 2011) According to Lee and Hong (2016), both informativeness and creativity, often emphasized in public literature, prove to be the main drivers of behavior favorable to advertisements on social networking services, promoting purchase intentions.

In addition, according to Dessart (2018), the commercial strategy must also involve balancing the elements of the narrative with facts. Using facts, figures and arguments only tends to alienate the individual and promote a distant attitude (Gottschal, 2012), but the symbiosis between the structure of the narrative and the elements of the story creates a powerful tool for transmitting information (Brechman \& Purvis 2015) and, when created efficiently, allows for more favorable cognitive responses, warm feelings and positive attitudes of the narrative advertisement, when compared to the advertising of arguments (Chang, 2009). Thus, we tested the following hypothesis:

H1: Creativity has a positive impact on narrative structure.

\subsection{Brand Congruence}

Consumers use brands that give meaning to their self-concept to themselves and to others (Aaker, 1999). The brand congruence theory evidences that people are satisfied with brands or products that are congruent with their actual or desired self-concept (Sirgy \& Su, 2000). So, brands represent social or cultural meaning congruent with consumer's own self-concept (Sirgy, 1982).

For Sirgy (1982) self-image congruity is a process whereby consumers purchase products/brands congruent with symbolic attributes similar to their images of themselves. This congruence has impacts on purchase behaviour, because consumers use products according with their self-image (Pedersen, Nysveen, \& Thorbjørnsen, 2003).

The consumer's mental representation of the self-concept consists in two essential aspects (e.g. Sirgy, 1982): the 'actual self' (one's self-image as it currently is) and the 'ideal self' (the image of oneself as one would like to be) that are linked to relevant motives that impact brand congruence: self-consistency and self-esteem (Sirgy, 1982).

Because "the consumer tends to purchase brands which have a similar image to his/her self-image" (Engel, 2001, p. 399). Some authors argue that self-brand congruence match with consumers self on dimensions on cultural values (Torelli et al., 2012), gender identity (Grohmann, 2009) and brand personality (Mulyanegara et al., 2007). Addictionally, narrative ads, and their creativity have an important role positive attitudes as a brand congruence (Gottschal, 2012). Therefore, we proposed the following hypotheses:

H2: Creativity has positive effects on brand congruence

H3: Narrative Ads Structure has positive effects on brand congruence 


\subsection{Social Media Engagement}

Consumer engagement has been defined in a number of ways in the literary, from emotional attachment to a brand (Calvert et al., 2014), to more cognitive, behavioral or emotional perspectives (Gambetti \& Graffigna, 2010). Hollebeek et al. (2014) define consumer brand engagement in social media as the ability to create a psychological state in the consumer's mind as they interact with the brand. This interaction in social media varies according to different levels of engagement from "following" (lower level) to "commenting" (higher level) (Pentina et al., 2018).

Tsai and Men (2013) based on consumers' brand related activities on online media (COBRA's) model of Muntinga, Moorman, and Smit's (2011) evidence two levels of engagement: passive consumption (e.g., viewing videos and pictures, reading product reviews) and active content contributing (e.g., responding to comments and other SNS posts, posting one's own product reviews, uploading user-created videos and pictures).

As a result, engagement in social media allows creating relationships between brands and multiple actors, engaging consumers (Westberg, Stavros, Smith, Munro, \& Argus, 2018), playing a strategic role in branding (Hajli, Shanmugam, Papagiannidis, Zahay, \& Richard, 2017). As consequence it also increases loyalty (Schivinski and Dabrowski, 2015), brand awareness/associations, perceived quality (Schivinski and Dabrowski, 2015) as well as purchases (Brodie et al., 2013).

Creative video ads increase motivation to process the ad and improve the attitude toward the ad (Lee \& Hong, 2016). Therefore, we proposed the following hypotheses:

H4: Creativity video ads is positive related with social media engagement.

H5: Narrative Ads Structure has positive effects on social media engagement.

Positive brand attitudes/evaluations (Graeff, 1997) and social media engagement appears as a consequence of self-brand congruence, because consumers express brand preference, loyalty and emotional attachment (Malär et al., 2011). Thus, we proposed the following hypothesis:

H6: Self Brand congruence is positively related with social media engagement.

\section{METHODOLOGY}

The research was conducted in a telecommunications industry. Telecommunications industry is a competitive industry, with low differentiation level of products and services, where advertising and creativity play an important role in competitiveness. In this environment, brands are changing their advertising to engage more and more customers. In context of COVID-19 pandemic environment, we analysed a Vodafone advertising video produced when people are in confinement (https://www.youtube.com/watch?v=Geus4SNwVkQ).

To test the proposed hypothesis, at first stage, a video ad was presented and, at a second stage, an online survey to collect data from telecommunications customers was conducted. All the measures were adapted from prior studies and have been confirmed to be reliable and valid. Before the questionnaires were distributed, all questions were translated into Portuguese by a specialized technician. Some items were slightly modified to fit telecommunications' advertising context.

\section{Measures}

In order to measure various constructs of the research model, the questionnaire uses a five point Likert scale, ranging from " 1 " to " 5 " (1=strongly disagree, 5=strongly agree). Specifically, creativity was measured using the items adapted from Lee and Hong (2016), narrative advertising structure was measured following Dessart (2018), brand congruence was measured by the items from Hinsch, Felix, and Rauschnabel (2020) and we measured engagement from Schivinski, Christodoulides, and Dabrowski (2016).

\section{Data collection Procedure and sample}

After translation, the questionnaire was pre-tested by a sample of 15 respondents. Based on your comments and suggestions, the formats and essays have been revised to ensure reliability and clarity. Information about the proposes of the study have been provided at the beginning of the questionnaire. The data were collected through a self-completion survey. The sample has 427 valid responses and the data collection took place from April to June 2020. The demographic profiles were reported in table 1. 
Table 1. Demographic profiles $(\mathrm{N}=427)$

\begin{tabular}{cccc}
\hline Variable & Category & Frequency & Valid \% \\
\hline Gender & Male & 123 & 28.8 \\
& Female & 304 & 71.2 \\
\hline Age & $<20$ years & 43 & 10.1 \\
& 20 to 29 years & 219 & 51.3 \\
& 30 to 39 years & 55 & 12.9 \\
& 40 to 49 years & 60 & 14.1 \\
& 50 to 59 years & 43 & 10.1 \\
& up to 60 years & 7 & 1.6 \\
\hline
\end{tabular}

Table 1 shows that $71,2 \%$ are female and most of the observations are originate from individuals below 40 years of age $(\mathrm{N}=274 ; 74,3 \%)$ (Table 1$)$.

\section{RESULTS}

The sample size of this study permits the usage of multivariate analysis techniques like Structural equation modelling (SEM) through maximum likelihood estimation, considering the rule of 5:1 (items:responses) (Hair, Black, Babin, \& Anderson, 2018). SEM is a multivariate analysis technique deployed to examine the proposed relationships. This technique that takes into account the measurement error in the model and it is recommended for theory testing in case of large datasets above 200 samples.

We used AMOS v.26 software and the research through SEM was analysed in two stages. First, the we analysed the measurement model (reliability and validity) and second, we analysed the relationship between constructs and evaluate the model fit.

\section{Preliminary data analysis}

At first step, common method bias was analysed, because data were collected from the same source and there have been a problem with commom method bias. To attend to this potential bias, ex-ante and ex-post procedures was employed. Ex-ante procedures were followed by Podsakoff, MacKenzie, Lee, and Podsakoff (2003) recommendations. We pre-test the survey to avoid vague concepts and complex syntax and double barrelled questions. At the first page of the survey respondents were informed that answers are anonymous and there are no right or wrong answers to each question. Ex post, Harman's one factor test was executed and the result showed four factors and fist factor explained $32.15 \%$ of the variance.

A preliminary data analysis was conducted and we ran a series of regression models on the various constructs to calculate the Variance Inflactor Factor (VIF). The VIF value is below the threshold (VIF <5) and therefore we assume that multicollinearity is not considered problematic. We also verified the Skewness (Sk) and Kurtosis $(\mathrm{Ku})$ and we concluded that the items do not diverge from normality $(\mathrm{Sk}<3$; Ku <7) (Hair et al., 2018). Additionally, we calculated the Kaiser-Meyer-Olkin (KMO) as well as Bartlett's test of sphericity to measure sampling adequacy. The KMO is $0.835(\mathrm{KMO}>0.7)$ and Bartlett's test is significant at $\mathrm{p}<0.05$. Therefore, the data are suitable for factor analysis.

\section{Measurement model}

The first step of the SEM analysis is the measurement analysis. We carried out the measurement model through confirmatory factor analysis (CFA) to assess reliability and validity. The results of model fit indices were acceptable $\left(\chi^{2}=261.884 ; d f=97 ; \mathrm{GFI}=0.929 ; \mathrm{CFI}=0.969 ; \mathrm{NFI}=0.951 ; \mathrm{IFI}=0.969 ; \mathrm{TLI}=0.961\right.$; RMSEA $=0.080)$. 
Table 2. Results of the measurement model

\begin{tabular}{|c|c|c|c|c|c|c|}
\hline $\begin{array}{l}\text { Variável } \\
\text { latente }\end{array}$ & Itens Code & $\lambda$ & $t$-values & $\mathbf{R}^{2}$ & CR & AVE \\
\hline \multirow[t]{4}{*}{ CREA } & & & & & 0.784 & 0.552 \\
\hline & CREA1 & 0.794 & (a) & 0.63 & & \\
\hline & CREA2 & 0.824 & 18.242 & 0.679 & & \\
\hline & CREA3 & 0.589 & 12.281 & 0.347 & & \\
\hline \multirow[t]{4}{*}{ NaST } & & & & & 0.840 & 0.636 \\
\hline & NaST1 & 0.809 & (a) & 0.655 & & \\
\hline & NaST2 & 0.834 & 17.014 & 0.696 & & \\
\hline & NaST3 & 0.747 & 15.535 & 0.558 & & \\
\hline \multirow[t]{4}{*}{ CONG } & & & & & 0.911 & 0.774 \\
\hline & CONG1 & 0.88 & (a) & 0.774 & & \\
\hline & CONG2 & 0.919 & 26.4 & 0.845 & & \\
\hline & CONG3 & 0.839 & 22.804 & 0.705 & & \\
\hline \multirow[t]{7}{*}{ ENG } & & & & & 0.943 & 0.735 \\
\hline & ENG1 & 0.828 & (a) & 0.686 & & \\
\hline & ENG2 & 0.821 & 29.555 & 0.674 & & \\
\hline & ENG3 & 0.874 & 22.552 & 0.764 & & \\
\hline & ENG4 & 0.875 & 22.592 & 0.765 & & \\
\hline & ENG5 & 0.894 & 23.413 & 0.799 & & \\
\hline & ENG6 & 0.850 & 21.566 & 0.722 & & \\
\hline
\end{tabular}

Convergent validity and reliability was examined through the Average Variance extracted (AVE) and Composite Reliability (CR) (Bagozzi \& Yi, 1988; Fornell \& Larcker, 1981). Thus, table 2 shows that AVE (ranging from 0.552 to 0.774 ) and CR (ranging from 0.784 to 0.943 ) are above the threshold values (AVE $>0.5 ; \mathrm{CR}>0.7)$. Additionally, we examine that standardized loadings $(\lambda)$ are above the recommended value for each construct $(\lambda>0.7)$ and their significance is considered $(p<0.05)$ (Chin, 1998).

Discriminant validity

Moreover, discriminant validity was examined. Table 3 present a Fornell and Larcker criterion (Fornell \& Larcker, 1981) to examine discriminant validity and we confirmed that all AVE values are higher than squared inter-construct correlation estimates.

Table 3. Discriminating Validity - criterion of Fornell and Larcker (1981)

\begin{tabular}{lcccc}
\hline Construct & CREA & NaST & CONG & ENG \\
\hline CREA & 0.552 & & & \\
NaST & 0.334 & 0.636 & & \\
CONG & 0.437 & 0.334 & 0.774 & \\
ENG & 0.387 & 0.097 & 0.336 & 0.735 \\
\hline Diagonal entries are AVE values; * all correlations are significant at level 1\% & \\
CREA=Creativity; NaST=Narrative Advertising Structure; CONG=Brand Congruence; \\
ENG=Social Networks Engagement;
\end{tabular}

The results indicate that constructs are unidimensional and show acceptable levels of reliability, convergent validity and discriminant validity.

\section{Structural Model}

The second step of the SEM analysis is the hypothesis testing through examination of the structural model and the results are shown in table 4 . The result of the chi square $\left(\chi^{2}\right)$ test is 365.007 with $d f=98$, which is statistically significant $(\mathrm{p}<0.01)$. Moreover, the global fit indices recommend that the model has an acceptable fit $(\mathrm{GFI}=0.901 ; \mathrm{CFI}=0.901$; NFI=0.932; $\mathrm{IFI}=0.949$; $\mathrm{TLI}=0.938$; RMSEA=0.080). The structural paths support hypotheses $\mathrm{H} 1, \mathrm{H} 2, \mathrm{~h} 3, \mathrm{H} 4, \mathrm{H} 5$ and $\mathrm{H} 6$. 
Table 4. Hypothesis Testing - Direct, Indirect and Total Effects

\begin{tabular}{|c|c|c|c|c|c|c|}
\hline Hip & Path & $\beta$ & Std Error & t-value & p-value & result \\
\hline H1 & $\mathrm{CREA} \rightarrow \mathrm{NaSt}$ & 0.577 & 0.045 & 10.16 & $p<0.001$ & Supported \\
\hline $\mathrm{H} 2$ & $\mathrm{CREA} \rightarrow \mathrm{CONG}$ & 0.491 & 0.063 & 8.42 & $p<0.001$ & Supported \\
\hline H3 & $\mathrm{NaSt} \rightarrow \mathrm{CONG}$ & 0.294 & 0.076 & 5,194 & $p<0.001$ & Supported \\
\hline $\mathrm{H} 4$ & $\mathrm{CREA} \rightarrow \mathrm{ENG}$ & 0.479 & 0.081 & 7.116 & $p<0.001$ & Supported \\
\hline H5 & $\mathrm{NaSt} \rightarrow \mathrm{ENG}$ & -0.184 & 0.089 & -3.1 & $p<0.01$ & Not Supported \\
\hline H6 & $\mathrm{CONG} \rightarrow \mathrm{ENG}$ & 0.376 & 0.071 & 5.935 & $p<0.001$ & Supported \\
\hline
\end{tabular}

\section{DISCUSSION}

The results evidenced the explanation of the engagement in social networks by the variables included in the model $\left(\mathrm{R}^{2}=0.461\right)$. The internet in general and social media networks specifically, generate content for users and the amount of information that they receive today is vast. This empirical study examined the creativity impacts on narrative structure. H1 is confirmed by our study $\left(\beta_{\mathrm{CREA}} \rightarrow \mathrm{NaSt}=0.577 ; p<0.001\right)$ as Chang (2009) states.

In order to test $\mathrm{H} 2\left(\beta_{\text {CREA }} \rightarrow \mathrm{CONG}=0.491 ; p<0.001\right)$ and $\mathrm{H} 3\left(\beta_{\mathrm{NaST}} \rightarrow \mathrm{CONG}=0.294 ; p<0.001\right)$, our investigation support that narrative ads, and their creativity has some effects on brand congruence. These conclusions corroborate Gottschal (2012).

To support the hypothesis $\mathrm{H} 4\left(\beta_{\mathrm{CREA}} \rightarrow \mathrm{ENG}=0.479 ; p<0.001\right)$, we analyse that creativity motivates the attitude toward social media engagement like Lee and Hong (2016).

Our empirical study do not support the positive relationship stated. The hypothesis H5 is not confirmed. We found some explanations for this. It is possible that the age of the respondents does not allow us to conclude about this relationship. In addition, our study has a sample with a strong percentage of women.

Finally, we state that $\mathrm{H} 6(\beta \mathrm{CONG} \rightarrow \mathrm{ENG}=0.376 ; p<0.001)$ is supported. This result is related with the conclusions of Malär et al. (2011).

\section{CONCLUSION}

Due to the centrality of social networks today, the empirical study presented here contributed to the advance of theoretical knowledge and has practical implications for management.

The study presents a model in which most of the causal relationships between the constructs were supported by our analysis. The model presented has a good fit.

This research concludes that there is a positive relationship creativity and narrative ad structure. Also demonstrates that brand congruence has effects from creativity and narrative structure. Additionally, social media engagement is explained throughout brand congruence.

Firms should reflect on these results and promote their creativity on video ad's to create mental representations on consumers' minds and, therefore, get more and mode engagement from their consumers.

Despite the important results, we considered that future researches could include other variables to help explain the model.

Thus, as further research, we suggest a model with the experience with the brand as a moderating variable.

In addition, our study only considered a sample of residents in Portugal. The analysis of users, from other countries, may be relevant for the explanation of the model presented. 


\section{ACKNOWLEDGEMENT}

This work is funded by National Funds through the FCT - Foundation for Science and Technology, I.P., within the scope of the project $\operatorname{Ref}^{\mathrm{a}}$ UIDB/05507/2020. Furthermore, we would like to thank the Centre for Studies in Education and Innovation (CI\&DEI) and the Polytechnic of Viseu for their support.

\section{REFERENCES}

Aaker, J. L. 1999. The malleable self: The role of self-expression in persuasion. Journal of Marketing Research, Vol. 36, No. 1, pp. 45-57.

Bagozzi, R. P., \& Yi, Y. 1988. On the evaluation of structural equation models. Journal of the Academy of Marketing Science, 16(1), 74-94. doi: 10.1007/BF02723327

Brechman, J. M. and Purvis, S. C., 2015. Narrative, transportation and advertising. International Journal of Advertising, Vol. 34, No 2, pp 366-381.

Brodie, R.J. et al, 2013. Consumer engagement in a virtual brand community: an exploratory analysis. Journal of Business Research, Vol. 66, No. 1, pp. 105-114.

Calvert et al., 2014. Using Implicit Methods to Develop an Objective Measure of Media Brand Engagement. International Journal of Market Research, Vol. 56, No. 1, pp. 15-32.

Chang, C. 2009. Being Hooked by editorial content: The implications for processing narrative advertising. Journal of Advertising. Vol. 38, No 1, pp 21-34.

Chin, W. 1998. The Partial Least Squares Approach to Structural Equation Modeling. Modern Methods for Business Research, 8.

Dessart, L. 2018. Do ads that tell a story always perform better? The role of character identification and character type in storytelling ads. International Journal of Research in Marketing. Vol. 35, No 2, pp. 289-304.

Engel, B. (2001). Consumer behavior. 9

Escalas, J. E. 2007. Self-referencing and persuasion: Narrative transportation versus analytical elaboration. Journal of Consumer Research. Vol. 33, pp 421-429.

Fornell, C., \& Larcker, D. F. 1981. Evaluating Structural Equation Models with Unobservable Variables and Measurement Error. Journal of Marketing Research, 18(1), 39-50. doi: 10.2307/3151312

and Graffigna, G. 2010. The concept of engagement. International Journal of Market Research, Vol. 52, No. 6, pp. 801-826.

Gao, Y., and Koufaris, M., 2006. Perceptual antecedents of user attitude in electoniccommerce. ACM SIGMIS, Vol. 37, pp 43-50.

Gottschall, J. 2012. The storytelling animal: How stories make us human. Boston, MA: Houghton Mifflin Harcourt Publishing Company.

Graeff, T. R. 1997. Consumption situations and the effects of brand image on consumers' brand evaluations. Psychology \& Marketing, Vol. 14, No.1, pp. 49-70.

Green, M. and Clark, J., 2012. Transportation into narrative worlds: implications for entertainment media influences on tobaco use. Society for Study of Addiction, Vol. 108, pp 477-484.

Green, M. C., and Brock, T. C., 2000. The role of transportation in the persuasiveness of public narratives. Journal of Personality and Social Psychology. Vol. 79, No.5, pp 701-721.

Grohmann, B. (2009). Gender dimensions of brand personality. Journal of Marketing Research, Vol. 46, No. 1, pp. 105-119.

Hair, J., Black, W., Babin, B., \& Anderson, R. 2018. Multivariate Data Analysis: Global Edition (8th ed.). New York: Annabel Ainscow.

Hajli, N. et al, 2017. Branding co-creation with members of online brand communities. Journal of Business Research, Vol. 70, pp. 136-144.

Harrigan, P. et al, 2017. Customer engagement with tourism social media brands. Tourism Management, Vol. 59, pp. 597-609.

Hinsch, C., Felix, R., \& Rauschnabel, P. A. 2020. Nostalgia beats the wow-effect: Inspiration, awe and meaningful associations in augmented reality marketing. Journal of Retailing and Consumer Services, 53, 101987. doi: https://doi.org/10.1016/j.jretconser.2019.101987

Hennig-Thurau, T. et al, 2010. The impact of new media on customer relationships. Journal of Service Research, Vol. 13, pp. $311-330$ 
Hollebeek, L.D. et al, 2014. Consumer brand engagement in social media: conceptualization, scale development and validation. Journal of Interactive Marketing, Vol. 28, No. 2, pp. 149-165.

Lee, J., and Hong, I. B., 2016. Predicting positive user responses to social media advertising: The roles of emotional appeal, informativeness, and creativity. International Journal of Information Management, Vol. 36, No 3, pp 360-373.

Malar, L. et al, 2011. Emotional brand attachment and brand personality: The relative importance of the actual and ideal self. Journal of Marketing, Vol. 75, No. 4, pp. 35-52.

Mulyanegara, R. et al, 2007. The big five and brand personality: Investigating the impact of consumer personality on preferences towards particular brand personality. Journal of Brand Management, Vol. 16, No. 4, pp. 234-247.

Muntinga, D.G. et al, 2011. Introducing COBRAs: exploring motivations for brand-related social media use. International Journal of Advertsiging, Vol. 30, No. 1, pp. 13-46.

Pentina, I. et al, 2018. Exploring social media engagement behaviors in the context of luxury brands. Journal of Advertising, Vol. 47, No.1, pp. 55-69

Pedersen, P. E. et al. 2003. Identity expression in the adoption of mobile services: The case of multimedia messaging services, Working Paper, 26, pp. 1-71

Podsakoff, P., MacKenzie, S., Lee, J.-Y., \& Podsakoff, N. 2003. Common Method Biases in Behavioral Research: A Critical Review of the Literature and Recommended Remedies. The Journal of applied psychology, 88, 879-903. doi: 10.1037/0021-9010.88.5.879

Schivinski, B., and Dabrowski, D., 2015. The impact of brand communication on brand equity through Facebook. Journal of Research in Interactive Marketing, Vol.9, No.1, pp. 31-53.

Schivinski, B., Christodoulides, G., \& Dabrowski, D. 2016. Measuring Consumers Engagement With Brand-Related Social-Media Content. Journal of Advertising Research, 56(1), 64. doi: 10.2501/JAR-2016-004

Sirgy, J. M. 1982. Self-concept in consumer behaviour: A critical review. Journal of Consumer Research, Vol. 9, pp. 287-300.

Sirgy, J. M., and Su, C.2000. Destination image, self-congruity and travel behaviour: Toward an integrative model. Journal of Travel Research, Vol. 38, No.4, pp. 224-235.

Tsai, W.-H. S. and Men, L.R. 2013. Motivations and antecedents of consumer engagement with brand pages on social networking sites. Journal of Research in Interactive Advertising, Vol. 13, No. 2, pp. 76-87.

Torelli, C. J. et al, 2012. Brand concepts as representations of human values: Do cultural congruity and compatibility between values matter? Journal of Marketing, Vol. 76, No. 4, pp. 92-108.

van Laer, T., de Ruyter, K., Visconti, L. M., \& Wetzels, M., 2014. The extended transportation-imagery model: A meta-analysis of the antecedents and consequences of consumers' narrative transportation. Journal of Consumer Research. Vol. 40, No 5, pp. 797-817.

Westberg, K. et al, 2018. An examination of how alcohol brands use sport to engage customers on social media. Drug and Alcohol Review, Vol. 37, No. 1, pp. 28-35 